\title{
IMAGINARIO SOCIAL E IDEOLOGÍA EN DISCURSOS PATRONALES DE SAX (1890-2010) Y RUBÍ (1890-2003) BAJO LA PERSPECTIVA RETÓRICO-PRAGMÁTICA
}

\author{
Xavier Laborda Gil \\ UNIVERSIDAD DE BARCELONA \\ xlaborda@ub.edu
}

Resumen: El artículo trata de la retórica de las salutaciones de las fiestas patronales en las localidades de Sax (Alicante, 1890-2010) y Rubí (Barcelona, 1890-2003). Estos corpus textuales proceden de los programa de las fiestas patronales. Los discursos reflejan vinculaciones institucionales, circunstancias históricas e influencias del periodismo y la publicidad. El estudio de las salutaciones, del subgénero epidíctico, muestra elementos de influencia ideológica y de creación del imaginario social. En los corpus de Sax y Rubí se aprecian las etapas informativa (1890-1930), ideológica (1931-1978) y publicitaria (1979-), en las que se pasa de una producción descriptiva (1890-1930) a otras de intención explícitamente ideológica (1931-1978) y, finalmente, publicitaria (1979-). Los discursos y los programas en que aparecen son constructos semióticos que reflejan discursos ideológicos y persuasivos sobre intereses sociales cambiantes, que cumplen finalidades de estabilización o de cuestionamiento de formas de poder. ${ }^{1}$

Palabras clave: Sax, Rubí, salutación, fiesta patronal, ideología, periodismo, publicidad. Abstract: "Social imaginary and ideology in patron speeches. A rhetoric and pragmatic study of the festive corpus of Sax (1890.2010) and Rubí (1890-2003)". The paper deals with the rhetoric of the saluta- tions of the festivities in the localities of Sax (Alicante, 1890-2010) and Rubí (Barcelona, 1890-2003). These textual corpus come from the program of the patron festivities. The speeches reflect institutional linkages, historical circumstances and influences of journalism and publicity. The study of salutations, of the epidictic subgenre, shows elements of ideological influence and creation of the social imaginary. The informative (1890-1930), ideological (1931-1978) and advertising (1979-) stages are shown in those corpus from Sax and Rubí, in which one goes from a descriptive production (1890-1930) to one of explicit ideology (1931-1978) and, finally, the advertising stage (1979-). The speeches and programs in which they appear are semiotic constructs that reflect ideological and persuasive discourses on changing social interests, which fulfill goals of stabilization or questioning of forms of power.

Keywords: Sax, Ruby, salutation, patronal feast, ideology, journalism, publicity. 


\section{LOS CORPUS DE SALUTACIONES DE SAX Y RUBÍ}

Este artículo trata de aspectos ideológicos y del imaginario social en dos poblaciones españolas a lo largo de algo más de un siglo. Contiene un estudio de recursos retóricos y pragmáticos de las salutaciones de las fiestas patronales en las localidades de Sax (Alicante, 1890-2010) y Rubí (Barcelona, 1890-2003). Estos corpus textuales proceden de los programa de sus fiestas patronales de San Blas, en Sax, y San Pedro, en Rubí. Los discursos documentan un largo período histórico y reflejan las vinculaciones institucionales y las influencias tanto de sus circunstancias como de los modelos textuales que imitan. Los conceptos con que se analiza estos discursos son la amplificación retórica y la construcción ética del emisor como causa de persuasión, así como la influencia del periodismo y la publicidad referida a las propiedades del texto.

Sax es una población alicantina de la comarca del Alto Vinalopó, cercana al municipio de Villena. Su población, que era de unos 3.000 habitantes a finales del siglo XIX, llega en la actualidad a los 10.000. Sus fiestas patronales de San Blas, en el 3 de febrero y los días aledaños, adquirieron a principios del siglo XIX el modelo de celebración de moros y cristianos propio de la Comunidad Valenciana, con simulacros de lucha, parlamentos de embajadas y desfiles de comparsas. Por su parte, Rubí es una localidad barcelonesa de la comarca del Vallès Occidental, cercana a Terrassa y a Barcelona. Respecto de su población, Rubí ha pasado de los cerca de 3.000 habitantes con que contaba a finales del siglo XIX a los 75.000 de ahora, con un fuerte crecimiento impulsado por factores concomitantes de emigración y de desarrollo industrial. Su fiesta mayor tiene como patrono a San Pedro, que se celebra el 29 de junio, con los actos populares del pregón, el pasacalle y las actuaciones de agrupaciones folclóricas.

El repertorio de salutaciones de fiesta mayor Celebratio et oratio (Laborda 2008) que hemos elaborado y publicado es un corpora especializado en comunicación institucional mediante discursos epidícticos o de celebración. De él proceden los corpus de Sax y Rubí. Este tipo de documentos constituye un recurso histórico de los siglos XIX y XX para el estudio de la comunicación, la historia local y la ideología. El corpora permite al investigador formarse un punto de vista privilegiado para reflexionar sobre el ámbito antropológico de la fiesta como un factor de identificación colectiva, memorial histórico y expresión de la variación lingüística.

${ }^{1}$ Este estudio se ha realizado en el proyecto FFI2015-64459-P, MEC (OFIL), "La evolución (inter)generacional de las bilingüizaciones: contextos, mantenimientos y substitución lingüísticos”. 
El análisis lingüístico del corpus de salutaciones (Laborda 2001: 96s; 2003) considera aspectos del género epidíctico (Menandro). El género de la salutación destaca por cuatro rasgos: disposición de secciones canónicas; recursos de amplificación; fórmulas expresivas y enfáticas; función de elogio de la fiesta y la comunidad. Con estos rasgos se define la modalidad estándar de salutación. Desde el punto de vista formal, cabe apreciar otras variedades a partir de este modelo canónico (Laborda 2001: 100ss).

El corpora Celebratio et oratio consta de sesenta y seis corpus de diferentes poblaciones españolas. Cada repertorio contiene las salutaciones inventariadas y, en algunos casos, la portada y otras páginas del programa de fiesta. Hemos realizado estudios de los corpus de las localidades barcelonesas de Sant Cugat del Vallès (Laborda 1999, 2001: 71-146) y Manlleu (Laborda 1912). Cada uno permite iluminar determinados mensajes y períodos históricos. La recopilación de programas de fiesta mayor y ferias de Sant Cugat del Vallès discurre entre 1928 y 2009. El análisis de su corpus se centra en las etapas de la transición política española y de la consolidación de la de mocracia, desde mediados de los años setenta hasta los noventa. El caso de Manlleu, con un corpus que cubre el período entre 1940 y 1957, ha resultado útil para conocer las influencias de la posguerra y del franquismo belicista en los discursos festivos. Finalmente, en el estudio que nos ocupa planteamos un examen paralelo de los repertorios de Sax y Rubí, para considerar los puntos de afinidad o divergencia y ampliar así la perspectiva analítica. Este trabajo comparativo supone seleccionar y abstraer los rasgos significativos.

Los repertorios del corpora más antiguos son los de Sax (Alicante, 18902010) y Rubí (1890-2003), precisamente los que estudiamos aquí. Sólo les precede en ese rango el corpus de Barcelona (1871-2007). En estos repertorios hay vacíos en lo que se refiere a diversos años, de modo que la documentación no está completa. Conviene notar que las salutaciones son textos que aparecen tardíamente en los programas de fiesta, por lo que las etapas contemporáneas resultan conceptualmente más ricas. No obstante estas circunstancias, los documentos recopilados permiten conocer el conjunto y comparar también tramos temporales, que constituyen los objetivos principales del estudio.

El repertorio de Sax contiene documentos de treinta y una ediciones festivas. En lo que se refiere a su distribución temporal, la primera mitad está cubierta con saltos, de modo que su contenido tiene una función ilustrativa de las épocas que incluye. A partir de 1958 hay una mayor continuidad entre los años recopilados, en particular a partir de 1976, de modo que el corpus permite el examen detallado de 
su curso ${ }^{2}$. Por su parte, el corpus de Rubí está documentado en setenta ediciones y constituye un conjunto discursivo regular y representativo. La parte más consistente, que se inicia en 1918 , cubre casi de manera completa un setenta y cinco por ciento del repertorio. ${ }^{3}$

\section{IDEOLOGÍA, FIESTA Y DISCURSO}

Los programas y las salutaciones de fiesta son una fuente de comunicación y, al mismo tiempo, matriz de conformación ideológica de la comunidad local. T. van Dijk se interesa por las relaciones que establecen el discurso y la cognición social para crear la ideología. Define la ideología como "un marco compartido de creencias que organizan y coordinan las interpretaciones y prácticas sociales de grupos y sus miembros" (1998: 22). Es una representación socialmente compartida que se caracteriza por dos rasgos: naturaleza abstracta y vinculación al poder. Tiene una naturaleza abstracta porque concibe la realidad de manera general, no en detalle. Está vinculada al poder, un factor que es su condición y propósito, para el ejercicio de dominio o de resistencia de unos grupos frente a otros.

En realidad no hay una ideología sino diversas ideologías. Éstas, por el juego de intereses de grupos, concurren en el marco social y colisionan o consiguen compromisos de articulación. En momentos de conflicto son evidentes las ideologías de dominación y de resistencia. En situaciones más equilibradas se dan ideologías de competencia entre grupos y también aquellas que promueven la cohesión interna de un grupo amplio o general, como sucede o se pretende que así sea en las celebraciones patronales.

El factor común a las estructuras de poder, sean de dominación o de solidaridad, es la función legitimadora que ejerce la ideología con sus producciones discursivas. La legitimación es la condición y el propósito de la hegemonía ideológica. Un efecto de la legitimación es segregar el espíritu de afiliación. La afiliación consiste

${ }^{2}$ Los años documentados en el corpus de Sax son 1890, 1892, 1899, 1900, 1902, 1906, 1915, 1916, 1924, 1930, 1936, 1958, 1959, 1960, 1963, 1966, 1068, 1069, 1974, y de 1976 hasta 2010, salvo 1994, 1995 y 1996. Por razones informáticas, el corpus está publicado en la red en tres archivos: volumen I (1890-1979, https://www.academia.edu/9334207/FM_Sax_1890-1979_Pla); volumen II (1980-1997, https://www.academia.edu/9334188/FM_Sax_1980-97_Pla); volumen III (19982010 https://www.academia.edu/9334169/FM_Sax_1998-2010_Pla).

${ }^{3}$ El corpus de Rubí contiene documentos de 1890, 1894, 1909, 1912, 1918-1922, 1925, y de 1927 a 2003 (salvo 1923, 1937, 1938, 1939, 1949 y 2001). Su publicación está divida en los archivos siguientes: volumen I (1890-1932, https://www.academia.edu/9371034/FM_Rubi_1890-1932_XavierLabordaGil); volumen II (1933-1968, https://www.academia.edu/9371014/FM_Rubi_193368_XavierLabordaGil); volumen III (1969-2003, https://www.academia.edu/9371004/ FM_Rubi_1969-2003_XavierLabordaGil). 
en motivar como una realidad natural diversos fenómenos de inclusión (Dijk 1998: 323). El más aparente de ellos, porque se suele explicitar verbal o semióticamente, es el sentimiento de pertenencia, sea a una organización, un grupo, una localidad o un país. La afiliación es sutil porque también está orientada a la adhesión a valores, objetivos y normas. Estos elementos ideológicos se manifiestan en acciones y signos de posición social, como la potestad para dirigir una salutación a los convecinos.

La fiesta patronal es un escenario de la actividad ideológica. En puridad apela a los fines inclusivos de una afiliación general. Si en la competencia política y económica las normas son selectivas, en el marco festivo se promueve la afiliación universal. Los días de celebración son una inversión del tiempo ordinario, pues postergan la contienda y, como excepción, proclaman el acceso igualitario a los recursos sociales que la fiesta aporta: ocio y diversión dionisíaca, rituales comunitarios y uso del espacio público.

La ideología tiene el efecto de la polarización de los grupos, que se manifiesta en la deixis "nosotros" frente a otros, que representa la idea de lo interior y propio frente a lo exterior. Por el contrario, la fiesta mayor inhibe esos principios disgregadores, aunque no los disuelve sino teóricamente, porque el acceso a los rituales y al espacio público, en concreto al discurso institucional de las salutaciones, está supeditado a restricciones. Y el uso del espacio público mediante los recursos simbólicos del discurso y la representación estamental legitima los principios ideológicos de determinado orden social.

No obstante estas observaciones positivas sobre la fiesta, también se ha de reconocer el carácter ambivalente de la producción simbólica que genera la fiesta. $\mathrm{Su}$ propósito más llamativo es la cohesión de la población, entendida como valor supremo en la comunidad, pero ello no cancela las acciones simultáneas de legitimación de valores e intereses que ejercen grupos políticos, religiosos y económicos. En este marco complejo, la ideología se perfila como un sistema de representaciones compartido socialmente. Su misión es guiar la competencia, el conflicto, la lucha y la desigualdad sociales (Dijk 1998: 22). La ideología, que regula también las prácticas sociales de la vida cotidiana, se enriquece con la excepcionalidad de la fiesta.

En el período festivo se sobrepone un marco compartido de creencias inclusivas y de afiliación general, que organiza y coordina las interpretaciones y prácticas sociales de los grupos y sus miembros como una sola comunidad. La fiesta es un epítome de la sociedad y su cultura, organización y ritmo, conflicto y cambio. El arquetipo de la vida es la fiesta, esa manifestación social de la dependencia y la acción colectiva. En la influencia recíproca que exige la fiesta, como contemplación y participación del espectáculo colectivo, se vive una experiencia que tiene influencia sobre la muerte al expulsarla temporalmente del imaginario colectivo. 
Las fiestas populares tienen la función de regular el calendario anual y de marcar el tiempo social. Lo hacen con rituales que apelan a pulsiones vitales y cohesionan el imaginario colectivo. También o precisamente por ello son fechas de holganza, exhibición de vigor físico, virtuosismo gastronómico, sensualidad musical, riqueza ornamental de cuerpos y lugares, ocasión para transacciones, invitación al galanteo y, fundamentalmente, el fascinante espectáculo que la colectividad se ofrece a sí misma (Capdevila y García 1997, Fòrum Barcelona 1998). ${ }^{4}$

\section{FIESTA Y COMUNICACIÓN INSTITUCIONAL}

La comunicación institucional es compleja y utiliza múltiples recursos, tales como el protocolo, la oratoria, la prosa normativa y la publicidad. El protocolo estipula el ritual y conforma una escenografía. La oratoria política desarrolla los contenidos conceptuales mediante un guión ideológico. La especialidad discursiva es la modalidad de la normativa administrativa. La publicidad, "el conjunto de artificios semióticos destinados a persuadir” (Hernández y Madrid 1999: 164), es una género tan versátil que lo mismo promueve lemas que crea acontecimientos públicos 5 .

El arquetipo de comunicación pública se encarna en el parlamentario y el candidato político (Menandro 285 a.C.). En la vida local, el mayor acontecimiento social suele ser la fiesta mayor y en ella hacen acto de presencia las instituciones, en particular el consistorio. La fiesta mayor es una tradición que late con fuerza en el imaginario popular porque está cargada de simbolismo y rituales que brotan de la pulsión erótica, entendida ésta como factor de sociabilidad y de ambición política (Capdevila y García 1997).

El repertorio de salutaciones de fiesta contiene discursos epidícticos o de celebración. Su lectura revela el curso histórico de estas producciones en el ámbito antropológico de la fiesta y examina su función de identificación colectiva y de documentación de referencias circunstanciales. El género epidíctico agrupa los discursos de lucimiento del orador, aquellos en que no se dirime el voto de una asamblea ni la sentencia de unos jueces, sino el reconocimiento o la repulsa que el público

\footnotetext{
${ }^{4}$ En relación a las fiestas populares desde el punto de vista antropológico e histórico, véase los trabajos de F. Cruces (1998) sobre la fiesta en Madrid, J. Escalera (1998) sobre Sevilla, A. F. Canales (1995) sobre Vilanova i la Geltrú (Barcelona), Laborda (1999, 2001:71-146) sobre Sant Cugat del Vallès y de J. Pablo (2000) sobre Barcelona.

5 Por su complejidad, la comunicación institucional ha sido objeto de estudio a partir de diferentes perspectivas: la de los medios de difusión, la acción política, la producción discursiva y el papel de los agentes en el proceso histórico (Redero 1996, Tezano 1993). Cada una de estas aproximaciones permite construir una visión histórica e ilustra sobre este campo de la vida pública (López Eire 2000).
} 
manifiesta del orador. Son discursos epidícticos el brindis, la conferencia, la reseña, el noticiario, el anuncio publicitario y la salutación de fiesta, por ejemplo ${ }^{6}$.

Las características esenciales de lo epidíctico se refieren a la finalidad, el estilo y el contenido (Romero 1989:10):

a) Finalidad lúdica, esto es, con una función que no es instrumental sino espectacular.

b) estilo elaborado o literario, más cercano a la poesía que en los géneros judicial y parlamentario;

c) contenido encomiástico o de vituperio, como rasgo intencional.

Estas tres características se resumen en un propósito, que es ofrecer a una audiencia el espectáculo de la prosa. El auditorio puede reconocer el entorno discursivo y asume el papel de valorar la elocuencia del orador. Las modalidades del género epidíctico son el encomio y la reprobación. La modalidad encomiástica consiste en la amplificación de intenciones, acciones y discursos prestigiosos, y la atribución de cualidades que se poseen. La reprobatoria consiste en lo contrario: atenuación de los méritos y amplificación de lo infamante. Los recursos retóricos que se aplican son la amplificación y la atenuación. Permiten exhibir y enaltecer o, por el contrario, ocultar y escamotear lo que sea propicio para el propósito del orador. La Retórica a Alejandro, del sofista Anaxímenes de Lámpsaco (s. IV a.C.), establece qué puede ser objeto de elogio: "Son elogiables los hechos justos, los legales, los convenientes, los nobles, los gratos y los fáciles de hacer".

Señala también el retor Anaxímenes que el discurso laudatorio debe presentar una organización de diversas partes: proemio, elogio de virtudes, genealogía y etapas del elogiado.

1. Proemio.- El proemio abre el discurso y tiene los cometidos de informar del contenido, captar la atención y despertar la simpatía de la audiencia.

2. Elogio de virtudes.- A continuación corresponde elogiar o vituperar. Son elogiables las cualidades que tienen su razón en la virtud: sabiduría, justicia, valentía, buenas costumbres. No lo son los bienes derivados de la fortuna o la herencia, como el linaje, la fuerza, la belleza o la riqueza, pero sí corresponde felicitar al afortunado. Llama la atención esta clasificación de las cualidades, que está trazada con el patrón de una ética heroica y arcaica, en contraste con

${ }^{6}$ Menandro describe en Sobre los géneros epidícticos (285 a.C) las modalidades del género: himno o encomio de dioses, ciudades, accidentes geográficos o genealogías. También lo son el epiraterio o salutación, el epitalamio o himno nupcial, la charla o combinación profesoral de deliberación y epidíctico, la charla propémtica o despedida, la invitación, la consolación y el epitafio. 
la ética utilitarista de la modernidad

3. Genealogía.- En la parte central corresponde tratar de la genealogía o antecedentes del sujeto u objeto de comentario. El elogio de los antepasados permite destacar la cadena de personalidades que vincula al homenajeado con una saga digna de mérito. Si no es así, se destaca que a pesar de ello el elogiado ha sido capaz de alcanzar una condición de mérito.

4. Etapas del elogiado.- Concluye el discurso con aspectos biográficos del elogiado, como los actos, la personalidad o los hábitos. Se señala que su condición es fruto del esfuerzo, no de la fortuna. Resultan apropiadas o destacables las cualidades relativas a la justicia, la sabiduría, la valentía.

En la organización del discurso, al final de cada parte se suele incluir una breve recapitulación de lo tratado. Y para concluir se recomienda incluir alguna sentencia o entimema, es decir, una argumentación verosímil. Esta notas sobre la amplificación retórica son una muestra de los recursos expresivos que se suelen aplicar en las salutaciones de fiesta.

\section{GUIÓN DE ESTUDIO}

La salutación forma parte del ritual de celebración de las fiestas. Entre los rituales para el elogio y la fiesta, hallamos una rica variedad de discursos epidícticos o apologéticos, ya sean ditirambos, citas, glosas, escolios, ejemplos, anecdotarios, testimonios, felicitaciones, exaltaciones, aclamaciones, brindis, epitalamios, lecciones, himnos y epitafios. Cada uno de ellos sirve un contenido particular, pero sigue un orden similar. Primero, la amistosa apelación a los presentes y el anuncio del homenaje. En segundo lugar, el agradecimientos a los organizadores y la presentación que hace el orador de sí mismo. A continuación, como parte principal del discurso, la justificación y el elogio del asunto. Para acabar, la frase exclamativa o epifonema con que se invita de modo exultante a participar del homenaje; como por ejemplo, “iViva la Fiesta Mayor!”.

Las salutaciones de fiesta y los programas que las contienen son un material precario porque su ciclo es corto y su interés queda reducido al coleccionismo. De ahí que resulte laborioso y difícil recomponer un corpus extenso de salutaciones. Las salutaciones son discursos de circunstancias y de vida efímera. Tienen una gran notoriedad en su momento de actualidad, que es breve, y están destinados al desecho. Suelen repetir tópicos cada año, de modo que su contenido resulta previsible y su voz parece ritual. No obstante estas características, su estudio revela matices 
significativos.

La investigación utiliza modelos y conceptos de la retórica y la pragmática para realizar el análisis del discurso en los siguientes ocho puntos.

1. Secciones de la salutación. 1.1 Título o etiqueta del género discursivo. 1.2 Destinatarios. 1.3 Anuncio de la fiesta. 1.4 Elogio de la fiesta y de la comunidad. 1.5 Organizadores. 1.6 Invitación. 1.7 Declaración anticipada de la fiesta. 1.8 Emisor.

2. Principios de la amplificación. 2.1 Causalidad o cosas asociadas a la localidad y la fiesta. 2.2 Efectos de la fiesta. 2.3 Cualidades elogiadas: propias de la virtud (sabiduría, justicia, valentía, buenas costumbres); impropias (linaje, fuerza, belleza, riqueza). 2.4 Antecedentes y etapas históricas.

3. Recursos retóricos de amplificación: Sinonimia, pleonasmo o redundancia léxica, enumeración, gradación u ordenación de elementos, paráfrasis o presentación de un concepto mediante una explicación, expolitio o presentación de un concepto de diversas maneras, hipérbole, figuras o analogías y tropos.

4. Estilo, norma y código lingüístico. 4.1 Estilo y registro expresivo (estándar, informal). 4.2 Norma y corrección tipográfica, ortográfica, sintáctica y léxica. 4.3 Código lingüístico o idiomas y variaciones dialectales.

5. El contexto en las deixis. 5.1 Emisor. 5.2 Destinatario. 5.3 Deixis sociales (estatus, proximidad o distancia). 5.4 Tiempo. 5.5 Lugar. 5.6 Deixis simbólicas.

6. Actos de habla. A. Aserción: 6.1 Constatación. B. Valoración: 6.2 Elogio (valoración positiva). 6.3 Vituperio (valoración negativa). C. Actuación: 6.4 Persuasión (incitación). 6.5 Disuasión (prevención).

7. Etapas históricas distinguibles formal y conceptualmente en el corpus.

8. Comentario final de valoración. 8.1 La elaboración del corpus: fuentes, dificultades y hallazgos. 8.2 Rasgos de los géneros epidíctico y de papelera en las salutaciones. 8.3 Discursos y vida local: contexto histórico y etapas. 8.4 Antropología de la fiesta: manifestaciones y cambios del ritual festivo. 8.5 Ideología y comunicación institucional: valores, consignas y carisma de agentes o emisores. 8.6 Anexo con la relación de documentación, fuentes e informantes.

De estos puntos de análisis, el primero resulta especialmente asequible y productivo porque consiste en distinguir su composición. En la salutación estándar distinguimos ocho secciones: título, destinatarios, anuncio de la fiesta, elogio de la fiesta, organizadores, invitación, declaración anticipada de la fiesta y emisor. Si bien el esquema de secciones puede variar, el núcleo de esta taxis o disposición canónica 
es el elogio de la fiesta y de la comunidad, de acuerdo con el espíritu del discurso epidíctico. La importancia del elogio comporta una mayor extensión mediante recursos retóricos de amplificación, como por ejemplo la mención de los miembros de la comunidad ("niños, jóvenes y mayores"), los antecedentes ("son unas fiestas tradicionalmente vinculadas a los ciclos del cultivo de la tierra, que luego se cristianizaron con la conmemoración del santo respectivo") o el uso de analogías y tropos ("el nuevo traje con que nos sorprende la ciudad, más bonita que nunca, llena de luz y color...”).

\section{ANUNCIO E IDEOLOGÍA}

La recopilación de programas de fiesta mayor de Sax (1890-2010) y Rubí (1890-2003) cubre algo más de un siglo. Su concepción, diseño y contenidos icónico-textuales son hijos del siglo XX. La revisión del esquema retórico de Menando y Anaxímenes de Lámpsaco, aun siendo instructiva, necesita la consideración de nuevos modelos semióticos para conocer las fuentes de los programas y sus salutaciones. Esos modelos son el periodismo y la publicidad, dos instrumentos comunicativos que han eclosionado con el siglo y que han adquirido una influencia poderosa.

En lo que se refiere al periodismo, Luis Alberto Hernández Cuadrado (2017: 18) señala cuatro etapas. Según un criterio teleológico, son las etapas ideológica, informativa, explicativa y digital. El periodismo ideológico, de carácter doctrinal y apologético, se desarrolla entre 1850 y 1917, al final de la Primera Guerra Mundial, con el artículo como género preferente. El periodismo informativo, que se solapa con el anterior desde 1870 y brilla entre 1920 y 1950, se basa en el relato de acontecimientos y explota los géneros informativos de la noticia y el reportaje. El periodismo de explicación, a partir de 1945, combina la intención de los anteriores en el reportaje en profundidad y la crónica, géneros que amalgaman el comentario y el relato con la adición del punto de vista del redactor. La condición híbrida de esa etapa explicativa se multiplica en la del periodismo digital, aparecida a finales del siglo XX, que avanza por un camino exploratorio en todos los aspectos semióticos.

La historia de la publicidad ha girado en torno a los dos polos en que se asienta el periodismo, la información y la opinión. En un primer período ha primado la publicidad argumentativa o denotativa y, con posterioridad, el emotivo o connotativo. Atendiendo a los recursos expresivos, J. M. Hernández y S. Madrid (1999: 189) distinguen en la publicidad de finales del siglo XIX la preeminencia del modelo argumentativo. Con él se "tiende a describir los productos comerciales en tanto en cuanto estaban provistos de un cierto valor de uso". Se apela al móvil instructivo, de 
modo que se informa de las características de un producto y de las ventajas de que proporciona. En el otro polo de estrategia se halla la publicidad emotiva, basada en valores y proyecciones afectivas, en significados indirectos y asociaciones indirectas al gusto del receptor. El hedonismo o principio de placer, que apela a móviles ético y pragmático, busca la gratificación de actuar por obligación moral o por utilidad.

Las referencias al periodismo y la publicidad, como géneros hegemónicos, constituyen una guía necesaria para interpretar los códigos semióticos de los programas de fiesta. Es obvio que los programas de fiesta aparecen como extensión de los medios de comunicación social, a los que imitan en formalidades expresivas y a cuyo prestigio se acogen con admiración. En el caso de la población de Sax, el programa de fiestas se ha convertido en una revista de notable envergadura y muy bien acogida.

La particularidad de los programas de fiestas, respecto del periodismo, es que su evolución es inversa, en el sentido de que en un principio cumple una labor informativa y luego añade a ésta elementos ideológicos, mediante la salutación, artículos y reportajes. El período estrictamente informativo llega hasta las dictaduras de M. Primo de Rivera y de D. Berenguer. Con la instauración de la II República, en 1931, y más aún a partir del franquismo, se inicia la etapa ideológica.

\section{ETAPA INFORMATIVA (1890-1930)}

Las informaciones que ofrecen los programas de fiestas de la etapa informativa, que se extiende de 1890 a 1930, tienen diversos contenidos, sean una enumeración de actos, un reglamento o una revista cultural y publicitaria.

\section{a) Programa de actos}

Se da la coincidencia de que las poblaciones de Sax (Alicante) y Rubí (Barcelona) inician la publicación de los programas en el mismo año de 1890. En aquel tiempo finisecular el programa era una hoja o suelto, con una discreta portada y la relación de actos de la semana festiva. En el caso de Sax, la hoja contiene un titular, un proemio del alcalde y el programa. El titular anuncia el "Grandioso y divertido festival que en la villa de Sax se celebrará en los días 1, 2, 3, 4 y 5 de febrero del presente año, en honor a su patrono el glorioso San Blas". Y antecede a la enumeración de actividades este texto de presentación, al estilo de un decreto administrativo:

Don Francisco Martínez Hellín, Alcalde constitucional de esta villa de Sax, hago saber: Que con el objeto de dar más suntuosidad y realce á la función cívico-religiosa que en esta Villa se celebra en honor de su Santo patrono San Blas; deseando que todos los vecinos de esta población sin menoscabo de sus 
ordinarias ocupaciones participen por igual de las honestas diversiones que este festival proporciona y procurando por que todo se haga con la mayor tranquilidad y armonía cual á un pueblo culto se reclama; en unión de la autoridad Eclesiástica, Mayordomos, Capitanes de Comparsas y demás individuos que participación tienen en esta grande función, se ha acordado disponer lo siguiente [el programa de fiestas].

El programa de Rubí coincide en la fecha de 1890 y difiere en lo demás. Con una artística portada modernista, convoca la entidad cívica Círcol (Círculo) de Rubí. Los actos, que duran una sola jornada, son audiciones musicales y zarzuela. Una crónica de la fiesta mayor de 1894, publicada en el periódico La Comarca (08-07-1894, pág. 6), confirma la suposición de que el programa contaba con más entidades y era más amplio de lo que enumera el programa de años atrás. "Nuestra Fiesta Mayor ha estado bastante desanimada”, asegura el redactor anónimo del comentario, que las considera "infantiles".

\section{b) Reglamento}

En 1899, el programa de Sax publica el reglamento de las "Grandes Fiestas de Moros y Cristianos”, que viene a ser una descripción detallada de los actos. Con la expresión de "Reglamento á que han de sujetarse los Capitanes, Comparsas y demás individuos que toman parte en esta festividad" se designa el protocolo o conjunto de normas de los actos festivos. Se les da así un rango oficial y solemne en un programa sucinto y preceptista, dedicado a establecer el comportamiento social. El programa cumple el propósito de una comunicación social en el estilo de un boletín de anuncios oficial. Para el primer día de fiestas, corresponde "al amanecer volteo general de campanas, anunciando que principio las fiestas". Y a continuación, “a las ocho de la mañana se repartirán bonos de pan y arroz á los pobres de este pueblo”, una acción que ayudaría a concitar un mejor ambiente en una situación de necesidad.

\section{c) Revista}

La Fiesta Mayor de Rubí de 1912 merece la publicación de un programa sobresaliente. Consiste en una revista cultural y una guía comercial de la localidad, elaborada con pericia periodística y editorial. En 28 páginas de comentarios, datos estadísticos y fotografías documentales, se expone la actualidad de la localidad de Rubí. Es de notar que una hoja basta para recoger el programa de fiestas, que se desarrolla entre el 29 de junio y el primero de julio. Refleja lo que puede ser una polaridad de organizadores y de posiciones políticas, en la Cámara Agrícola y el Centro Democrático Republicano. 
Según la guía, Rubí contaba con 1.283 edificios, y el censo de 4.430 habitantes se dividía en " 2.120 varones y 2.304 hembras". Las informaciones más relevantes sobre la villa, ilustradas con la novedad de fotografías, se recogieron en el programa extraordinario de 1912: corporación municipal, horarios y destinos del ómnibus o autobús, maestros y centros educativos, fábricas y tipo de actividad, miembros de los gremios, chalets y edificios públicos, calles y paseos.

El anuario de 2012 se completó con notas históricas y artículos. Incluía panegíricos literarios en catalán, como el poema "Oda a Rubí" o la glosa nostálgica "Recordant a ma benvolguda mare”. También recogió artículos sobre economía local, deporte y viajes. La opinión halló un lugar en artículos de enfático título, como "Por la transformación de Rubí”, "Por la transformación de España” y "Patria y patriotismo”, en las que el análisis corteja el manifiesto político.

El formato de revista, poco frecuente en esta etapa informativa, llegará a ser usual en los programas de fiestas de Sax más adelante, hasta convertirse en el alarde editorial que es en la actualidad, como en muchas otras localidades levantinas. Un antecedente de Sax se halla en el programa de 1919, que reparte por un igual sus dieciocho páginas entre la relación de actos y publicidad local.

\section{ETAPA IDEOLÓGICA (1931-1978)}

La etapa ideológica, entre 1931 y 1978, cubre el período de la II República y el franquismo. En ella se produce un vuelco institucional y discursivo. La impronta de la fiesta mayor en el calendario anual es grande y se amplía con el transcurso de las ediciones como foro ideológico. Favorece esa evolución el desarrollo económico y el progreso técnico de la prensa, que asisten a la intensa contienda política de entreguerras. Tras la Guerra Civil española, la dictadura franquista se adueña de los discursos de fiesta.

En la etapa explícitamente ideológica, aquella en que se produce la novedad de incluir discursos de saludo, distinguimos los períodos de debate político y adoctrinamiento. En estos períodos aparece y se utiliza el género de la salutación de fiesta, una modalidad híbrida de brindis y artículo de opinión, con la que se comunica los valores ideológicos de las circunstancias históricas. Se observa que la publicación extraordinaria del programa de fiestas sigue un proceso inverso al del periodismo, en el sentido de que pone el énfasis -cuando menos, desde el punto de vista de nuestro análisis- en el artículo o escrito de opinión. 


\section{a) Debate politico}

La primera salutación de los repertorios aparece en 1931 en Rubí. Es la primera que contiene un mensaje que va más allá de la cortesía de anuncio de fiesta. Aparece en la publicación quincenal La Lluita (La Lucha), que edita el Centre Democràtic Republicà. La portada de la revista está dedicada a la fiesta mayor. En ella se lee la relación de actos de esta entidad política y la salutación, que está redactada al estilo de una editorial y en catalán, una lengua que había estado prohibida. Aprovecha la convocatoria de fiesta para hacer un balance de la persecución padecida y de las expectativas de libertad que se abren. El párrafo inicial, traducido del catalán, dice así:

Convencidos estamos de que hogaño los socios de nuestro Centro podremos disfrutar plenamente de esta Fiesta Mayor, la cual, por ser la primera desde la proclamación de la República, no tendrá la tristeza y la amenaza encubierta que existía en las pasadas, por obra y gracia de los dictadorcillos que campaban, contra la voluntad el pueblo, dando un ambiente gris e impidiendo a éste que exteriorizara la alegría que es característica de las manifestaciones en que desea expansionarse. [La Lluita, 27-06-1931, pág. 1]

Es revelador del tipo de lector a que está destinada la publicación el estilo del texto. El párrafo, compuesto de una cláusula, indica que el periodista cuenta con la atención del lector. El fragmento es un discurso completo por sí mismo y de una rica composición. Se inicia con el anuncio de la fiesta y concluye con el mismo asunto, mediante la descripción de sus características, la alegría y la expansión. En medio de ello dispone el redactor la cuestión de la crítica política. Así pues, celebra el advenimiento de la República y censura los “dictadorcillos” Primo y Berenguer. La perspicacia del escritor se aprecia en que, a modo de ejemplo, vincula la dictadura a la ruina del espíritu de fiesta.

La salutación tiene dos párrafos más, que permiten ampliar la argumentación política. En uno se recoge lo negativo del pasado inmediato, la "autoridad despótica” y los "atropellos" contra la libertad de una "caducada Monarquía”. En el último párrafo se invoca con "esperanza" el "cambio radical” de la "libertad", en la que se deposita "confianza” y se espera vivir con "alegría”. El ideal de La Lluita -así concluye el escrito- es que los políticos "representen los intereses comunales del Pueblo".

\section{b) Adoctrinamiento}

Los peligros que temía el redactor de La Lluita, personificados en los "amos y señores de las voluntades y los derechos ciudadanos”, se abatieron sobre España. El 
franquismo disolvió entidades como el Centre Democràtic de Rubí y su órgano de prensa. Con impunidad la dictadura usurpó el podio de la fiesta mayor para proclamar su ideología totalitaria. El programa de fiestas de 1951 de Rubí contiene una salutación representativa de este período de adoctrinamiento. Un tono clerical concita inevitablemente argumentos religiosos, al gusto del carlismo eclesiástico que recaló en la parroquia. En el anuncio de la fiesta se lee un mensaje embargado de unción, en una estampa dominical y familiar.

Rubí se dispone al descanso por un breve tiempo en su cotidiano acontecer para rendir culto a su glorioso Patrón San Pedro, y para dar solaz al espíritu, en públicas y familiares diversiones.

Aunque parezca contradictorio con la ocasión por el tono devoto y de recogimiento, se expresa un deseo:

Quiera Dios que en los hogares rubinenses reine en estos días la alegría sana y honesta y abra un vivir fraternal y optimista ante todos.

Llama la atención que el escenario festivo que se concibe en la salutación no es la calle ni el salón social, sino el del hogar. Esta incursión ideológica en la vida privada indica dos rasgos: la atribución de entremeterse en la vida privada y la expulsión conceptual de la fiesta como actividad pública. El adoctrinamiento va más allá de mensajes implícitos y proclama sus valores: la tradición y la paz, en un país que el historiador Borja de Riquer (2010) califica de cuartel y campo de concentración laboral.

Hermanar la tradición en la laboriosidad y la tradición en las Fiestas, ha sido siempre la característica de la singular fisonomía rubienense. Añadamos a ella la belleza de nuestros paseos y plazas con sus cuidados jardines y esbeltos edificios, mientras en otras zonas importantes industrias elevan al espacio la oración del trabajo, con el campo agrícola muy repartido y las cada día más crecientes zonas en urbanización, esa es nuestra villa, reducto de serena y cómoda paz, a escasa distancia del torbellino arrebatador de la capital.

La identificación del régimen con la tradición concuerda con la estampa de elementos estáticos: un urbanismo atractivo, fábricas donde el trabajo es oración y un mundo agrícola ubicuo. Con un dramatismo retórico, ese "reducto de serena y cómoda paz", que lo sería para la jerarquía y los industriales, contrasta con el in- 
quietante "torbellino arrebatador de la capital", localizado en la cercana y peligrosa Barcelona. Paradójicamente el símil militar del reducto, un parapeto de campaña defensivo, tanto puede ser un motivo de orgullo como de una resistencia agónica. Sea como fuere, el mal existe, pero está en otro lugar.

En el repertorio de Sax la primera salutación con contenido ideológico que conocemos aparece en el programa de 1958. En el siguiente año, el programa publica las salutaciones del alcalde, el párroco y la mayordomía o comisión de festejos. La multiplicidad de voces públicas manifiesta el reparto de las atribuciones política, confesional y organizativa. Es curioso que en un mundo afecto a la tradición, como sucedía en Sax y en Rubí, se asuma con naturalidad la novedad de diversos agentes sociales al frente de las fiestas. En el caso de Sax, con el paso del tiempo, las autoridades que saludan aumentan hasta un número inverosímil, entre los cuales están la familia real, el presidente de la Diputación, el alcalde de la localidad hermana de Alagón y el presidente de la Generalitat Valenciana.

La mera firma de salutaciones por parte de las autoridades mencionadas en el corpus de Sax, con frases protocolarias, basta para ejercer la función adoctrinadora. No es necesario que entren en disquisiciones políticas, porque no se discute el principio ideológico de la tradición. La apelación al purismo tradicional, que hace acto de presencia en cada discurso, es una sinécdoque del orden general, al que se debe acatamiento. Este comportamiento se quiebra tras la muerte de Franco, en que las autoridades prescinden de la excusa festiva y se despachan contra la democracia. En 1978, meses antes de aprobarse la Constitución, el alcalde manifiesta su deseo de "convivencia pacífica", como si fuera un bien en peligro y en el Régimen que le había nombrado estuviera exento de responsabilidad. El escrito de este mismo año de la Mayordomía o comisión de fiestas restalla como un látigo, ya de buen comienzo.

En nuestra constante preocupación por (...) la fiesta, este año, y como consecuencia del momento que vivimos, queremos señalar algunos de los problemas en que se va a ver envuelta. Nos referimos al torbellino de nuestra incipiente democracia y a las posibilidades de apoyo que, como entidades de base popular como son las Organizaciones Festeras, puede proporcionar a personas o grupos que se lo propongan.

La mezcla de reticencia y franqueza impregna de sabor el párrafo inicial. El "momento que vivimos" traerá problemas, porque son el efecto del "torbellino de nuestra incipiente democracia”, expresión en que reconocemos el aprecio de la metáfora atmosférica como idea de riesgo. Lo que preocupa a la Mayordomía es que se utilice la fiesta para manifestaciones políticas, algo inaceptable en el mayor aconte- 
cimiento de la villa de Sax. Precisamente las nuevas voces podrían pensar que, por la importancia social de las fiestas, podía ser esa la ocasión de significarse. "Defendemos los valores espirituales de la fiesta”, argumenta la Mayordomía, “y es nuestra opinión que la fiesta no debe tener ideologías ni debe sufrir los envites de éstas”. Su razonamiento es congruente con la idea de que las nuevas ideas políticas eran ideología. Se infiere que el franquismo, no.

\section{ETAPA PUBLICITARIA (1979-)}

Con la restauración de la democracia, la autoridad municipal -electa por primera vez en mayo de 1979- se acoge a la tradición del saludo para divulgar mensajes del gobierno local, pero también y especialmente para promocionar el carisma político. Muestra una evolución de las pautas discursivas de la etapa ideológica a las propias de una publicidad ágil y atractiva, que divulga la idea de la ciudad y su alcalde como un valor, en vez de un gestor. El gobierno local realiza de este modo una propaganda implícita, en elogio de una formación política y de su dirigente.

En la localidad de Rubí, el proceso sigue tres fases. La del manifiesto es la reacción de ruptura con el adoctrinamiento dictatorial y representa una voz coral. Le siguen las del líder político y, más delante, de afianzamiento de su figura carismática, en un proceso de desvanecimiento del coro, que intervenía en el manifiesto, y la emergencia del solista.

Manifiesto (1979-1980).- No se incluye salutación alguna, lo que implica que no hay una intención persuasiva ni nadie asume el protagonismo. Con esta supresión se rompe con la tradición de dominio y, al mismo tiempo, se expresa una búsqueda crítica de modelos. Sólo figura en la cabecera del programa de 1979 el radiante lema "Ara és la nostra" ("Ahora es la nuestra"), que cumple el cometido de un conciso manifiesto colectivo. Al año siguiente, un "Som-hi tots!" (“iVamos todos!") sigue el mismo patrón.

Promoción del líder (1981-1988).- Se incluye la salutación del alcalde, Miquel Llugany. Esta vuelta al género acaba con el proceso asambleario, al presentar y afianzar la figura del líder político en la persona del alcalde. "Trabajemos la ilusión" es el lema de 1982, en cuya salutación hace un balance de lo que significa la fiesta en democracia:

Ahora, después de tres años, resultaría muy difícil apartarnos de estas costumbres tan nuestras y tan fáciles de aprender cuando se nos permite hacerlo: Participar y estar. Ahora nos resultaría difícil dejar de estar en la calle, pasear, hablar. 
Todo esto, ahora, es nuestro.

Discurso presidencial (1989-).- El emisor es una personalidad carismática que domina el género y que acompaña con su retrato. En el saludo incluye a menudo menciones circunstanciales, ajenas a la fiesta, como por ejemplo la mención a las iniciativas del gobierno municipal. El fragmento que sigue procede del programa de 1990.

La Fiesta será como siempre y mejor. (...) Será la de Rubí y basta. Sin mirar atrás, porque amigos, si nuestra Fiesta va adelante, es porque la ciudad también va. O es al revés. ¡No!, es inseparable. Estamos contentos, vamos hacia adelante, mejoramos, la Fiesta también.

El emisor asume un papel presidencial en la fiesta. Este modelo de dominio carismático, con una función promocional, se ha impuesto como una convención.

En Sax se producen menos cambios que en Rubí, de modo que el uso de la salutación queda en un término medio, puesto que no difiere tanto del patrón del adoctrinamiento, ni llega luego al registro del discurso presidencial o carismático. Por lo tanto, en Sax no se pasa por la fase del manifiesto de los valores democráticos en las salutaciones. La dinámica de las fiestas permite una continuidad formal entre la dictadura y el régimen constitucional. Se aprecia en el repertorio las fases de la promoción del líder y del patrono corporativo de las fiestas.

Promoción del lider (1980-1988).- El primer programa con un alcalde electo -en mayo de 1979- es de febrero de 1980. A partir de esta fecha, los discursos están firmados por el alcalde, Ramón Hurtado (1980), y en los años sucesivos por Pedro Barceló (1981-1988). El "saludo de la alcaldía” de 1984, por ejemplo, no solo muestra la inclusión de referencias consistoriales en la comunicación festiva, sino que constituye casi la totalidad de él.

Intervengo como alcalde en esta segunda etapa de Ayuntamiento Democrático. Ello, me anima y obliga a acrecentar mi entusiasmo y dedicación en trabajar sin desmayo para corresponder y hacerme acreedor de esa confianza, que procuraré, a toda costa, no quede defraudada. (...) Es imprescindible que colaboremos todos los ciudadanos, aportando nuestro grano de arena para hacer un pueblo cordial, cívico y más humano, del que nos podamos sentir orgullosos como sajeños, El Ayuntamiento está luchando por facilitar al pueblo los medios necesarios, tanto de infraestructura urbanística, como de servicios que permitan la promoción de la cultura, la enseñanza, el deporte, festejos, etc., 
para que pueda ser realidad el hacer un gran pueblo.

El alcalde Pedro Barceló se sirve con desenvoltura del saludo, sin una ruptura con las prácticas discursivas del antiguo régimen. Con la autoridad de su función política, en el programa de 1986 hace unas recomendaciones sobre la limpieza de fachadas del pueblo:

Con la limpieza y decoración de las fachadas de nuestras casas, que rivalizan en belleza para sorprender agradablemente a nuestros amigos y visitantes y para recibir a nuestro Patrono San Blas en su recorrido por la población. Esta labor de embellecimiento es digna de alabanza, pero lo deseable es que esos arreglos y limpieza de nuestras fachadas se realicen durante todo el año, pues no olvidemos que nuestro pueblo es el lugar en donde habitamos y convivimos con nuestros vecinos y amigos durante algo más de cinco días. Por ello animo a mis convecinos a que sigan en esta tónica.

Patrono corporativo de las fiestas (1989-).- En 1989 toma la palabra en el programa un nuevo alcalde, Francisco Estevan Molina, y desde 1992, Juan Gil. La novedad es que aparecen con su retrato. Se afianza así la figura del líder político, pero el efecto es menor que en el repertorio de Rubí porque comparte las salutaciones con otras personalidades institucionales y, además, elude tratar de cuestiones políticas. Por otra parte, el programa de fiestas de Sax es en realidad una gran revista, de centenares de páginas y editada con primor, en la que se incluye numerosas fotografías de los festeros, artículos y una extensa sección de publicidad. El alcalde tiene un papel destacado, pero no entra en contenidos de la agenda consistorial, ya que se centra en su función de patrono de la fiesta. Las salutaciones del período destacan por unas fórmulas expresivas estereotipadas y por un tono festivo. El tono es positivo, jovial y vehemente, en consonancia con la ocasión festiva.

\section{CONCLUSIÓN: ANTROPOLOGÍA TEXTUAL E IDEOLOGÍA}

Hemos examinado las salutaciones de las fiestas patronales en las localidades de Sax (Alicante, 1890-2010) y Rubí (Barcelona, 1890-2003). Estos corpus textuales proceden de los programa de sus fiestas patronales de San Blas y San Pedro, respectivamente. Los discursos reflejan las vinculaciones institucionales y las influencias de sus circunstancias y de los modelos textuales que imitan. El interés del estudio de la salutación de fiesta es doble, pues radica tanto en el contenido ideológico de los 
corpus como en la tipología textual. Permite plantear cuestiones sobre textos y géneros discursivos. También, sobre sus agentes y las pautas del entorno comunicativo.

Desde el punto de vita de la antropología textual, consideramos la ideología y los fenómenos de afirmación de la vida en la fiesta como aspectos de la acción social. La ideología es el marco compartido de creencias que organizan y coordinan las interpretaciones y las prácticas sociales. Con los discursos de fiesta se crea un espacio simbólico en que la comunidad reconoce el cuerpo simbólico de sus miembros y produce efectos de poder. En el período festivo se sobrepone a las divergencias ordinarias un marco compartido de creencias inclusivas y de afiliación general, que organizan a los grupos y sus miembros como una sola comunidad.

Las producciones del género epidíctico - discursos de encomio y censura- muestran una realidad compleja, cambiante y significativa. Para su estudio consideramos la amplificación retórica, como fuente histórica, y la influencia contemporánea del periodismo y la publicidad. Los comentarios epidícticos se refieren a la finalidad lúdica, el estilo elaborado y el contenido encomiástico o de vituperio. Según la tradición, en su composición intervienen las partes del proemio, el elogio de virtudes, la genealogía y las etapas del elogiado.

El periodismo se ha desarrollado, a partir de 1850, en las etapas ideológica -doctrinal y apologética, con el género del artículo-, informativa -relatora de acontecimientos, con la noticia y el reportaje-, explicativa -combinación de lo anterior con el punto de vista del redactor, en la crónica- y, actualmente, la digital. Por su parte, la historia de la publicidad ha girado en torno a los dos polos en que se asienta el periodismo, la información y la opinión. En un primer período ha primado la publicidad argumentativa o denotativa, que busca convencer con informaciones, y más tarde la publicidad emotiva o connotativa, que persuade mediante la gratificación hedonista.

Los géneros hegemónicos del periodismo y la publicidad son la guía de los códigos semióticos de los programas de fiesta. Los programas imitan estos medios de comunicación social en formatos y recursos expresivos. La particularidad de los programas de fiestas, respecto del periodismo, es que su evolución es inversa, en el sentido de que en un principio cumple una labor informativa y luego añade a ésta elementos ideológicos, mediante la salutación, artículos y reportajes.

En los corpus de Sax y Rubí se aprecia tres etapas, la informativa (1890-1930), la ideológica (1931-1978) y la publicitaria (1979-). En la inicial o informativa, los contenidos de los programas varían, según sea una escueta enumeración de actos, un reglamento de actos o el alarde editorial de una revista. La etapa ideológica se caracteriza por incluir discursos de saludo, que, según el régimen político, presenta los períodos de debate político y de adoctrinamiento. A su vez, la etapa publicitaria consiste en una ruptura con el patrón doctrinario, mediante una fase de manifiesto político, en la que 
habla una voz comunitaria, que luego pasa por las fases del liderazgo del alcalde y de la promoción de su figura como agente presidencial o preeminente. En esta etapa se aplica códigos semióticos de la publicidad, con retratos, logotipos y diseños atractivos, para destacar no tanto informaciones como valores de la marca de la población y de sus dirigentes.

La evolución de los programas de fiesta de las dos localidades muestra unos inicios similares en formato y finalidad comunicativa, pero unas diferencias grandes en la actualidad. La brevedad de las primeras ediciones basta para el propósito del anuncio de los actos de la fiesta. En Rubí toman la iniciativa las entidades cívicas, mientras que en Sax, por el carácter procesional de los festejos, se elabora una publicación conjunta auspiciada por la autoridad consistorial. La iniciativa de editar una revista extraordinaria para aprovechar la ocasión aparece en Rubí en 1912 y, con un rango menor, la guía comercial de Sax en 1919. El desquite llega mucho después, en 1963, fecha a partir de la que Sax elabora una ostentosa revista de fiestas, mientras que en Rubí el programa de fiestas ha continuado en los límites prototípicos del folleto.

En lo tocante a los contenidos, los programas de fiesta de Rubí han expresado una intención ideológica más explícita que los de Sax y han tenido fluctuaciones considerables según las épocas. Si el valor de la tradición ha sido una motivación que aparecía en muchas ediciones, también las hay de tipo transgresor, con mensajes de debate y elecciones cambiantes. En Sax la tipología de festejo ceremonial ha favorecido un comportamiento morigerado, con un perfil aparentemente bajo en producción ideológica. El valor de la tradición ha regido las manifestaciones editoriales y se ha intensificado su difusión con la presencia de numerosas autoridades, un fenómeno de hipertrofia de salutaciones que difunde ideología institucional de manera percutiva.

El estudio de estos textos del género epidíctico, aunque en apariencia pasen por menores, aporta una perspectiva diacrónica que permite establecer modalidades del género y sus tópicos, los conflictos ideológicos y las negociaciones discursivas. Los repertorios discursivos son una fuente de la oratoria apologética o espectacular del siglo XX. Más aún, guardan la memoria de escenarios simbólicos en que se ha producido la acción pública, la identificación colectiva, la legitimación política y la propaganda institucional.

En este tipo de investigación se combina los ámbitos del discurso, las instituciones políticas, el protocolo, la ideología y la tradición popular, bajo una perspectiva histórica. Los programas en de fiesta son constructos semióticos que reflejan discursos ideológicos y persuasivos sobre intereses sociales cambiantes, que cumplen finalidades de estabilización o bien de cuestionamiento de las formas de poder. El análisis de los discursos festivos revela sentidos en que la comunidad local funciona y evoluciona, para así explicarla y hacerla inteligible. 


\section{REFERENCIAS BIBLIOGRÁFICAS}

Anaxímenes de Lámpsaco (s. IV a.C.): Retórica a Alejandro. Salamanca: Universidad de Salamanca, 1989.

Aristóteles (350-335 a.C.): Retórica. Madrid: Centro de Estudios Constitucionales, 1990.

Canales, Antonio Francisco (1995): La festa major de Vilanova i la Geltrú al segle XX. Vilanova i la Geltrú: Consell Comarcal del Garraf.

Capdevila, Joaquim y Agustí García Larios (eds.) (1997): La festa a Catalunya. La festa com a vehicle de sociabilitat i d'expressió politica. Barcelona: Publicacions de l'Abadia de Montserrat.

Cruces, Francisco (1998): "Les festes a Madrid (1977-1993)" en Fòrum Barcelona Tradició (1998): Festa i Ciutat. Barcelona: Institut de Cultura de l'Ajuntament de Barcelona-Edicions el Mèdol.

Dijk, Teun A. Van (1998): Ideología. Una aproximación multidisciplinar. Barcelona: Gedisa.

Escalera, Javier (1998): "Les festes com a patrimoni: reflexions sobre la festa a la ciutat contemporània a partir del cas de Sevilla” en Fòrum Barcelona Tradició (1998), Festa i ciutat. Barcelona: Institut de Cultura de l'Ajuntament de Barcelona-Edicions el Mèdol.

Fòrum Barcelona Tradició. (1998): Festa i ciutat. Barcelona: Institut de Cultura de l'Ajuntament de Barcelona-Edicions el Mèdol, Vol 1.

Hernández, José Miguel y Sonia Madrid (1999): “Recursos retóricos de la publicidad española entre siglos” en Revista de Investigación Lingüisica. N. 2, Vol. II, 163-208.

Laborda, Xavier (2012): “Comunicación institucional y prensa local de Manlleu en el franquismo, 1940-1957” en Tonos Digital. N. 22 (I-2012).

- (2008): “Corpora de salutaciones de Fiesta Mayor” en Academia: https:// ub.academia.edu/XavierLaborda/Celebration-and-speech.

- (2008): "Celebratio et oratio. Corpora de discursos epidícticos para el análisis de la comunicación institucional” en Linred. VI, 16-11-08

- (2003): "Propaganda institucional y literatura de papelera. Teatro político de contienda y de autoalabanza en Cataluña" en Revista de Investigación Lingüistica. N. 2, Vol. VI, 43-66.

- (2001): Comunicació institucional i literatura de paperera. València: Editorial 3 i 4 .

- (1999): "Salutacions de la Democràcia en festes" en Gausac. 14 (VI-1999) 43-72. 
López Eire, Antonio (2002): Poéticas y Retóricas griegas. Madrid: Síntesis.

López Eire, Antonio y Javier de Santiago Guervós (2000): Retórica y comunicación política. Madrid: Cátedra.

Menandro (circa 285 a.C.): Sobre los géneros epidícticos. Salamanca: Universidad de Salamanca, 1989.

Pablo, Jordi (2000): La Mercè il.lustrada. Tarragona: Ed. Mèdol,

Redero San Román, Manuel (ed.) (1996): La transición democrática en España. Madrid: Marcial Pons.

Riquer, Borja de (2010): La dictadura de Franco. Barcelona: Crítica-Marcial Pons.

Romero Cruz, Francisco (1989): “Introducción” en Menandro, Sobre los géneros epidícticos. Salamanca: Universidad de Salamanca.

Sánchez Sanz, José (1989): “Introducción” en Anaxímenes de Lámpsaco. Retórica a Alejandro. Salamanca: Universidad de Salamanca.

Fecha de recepción: 23 de junio de 2018

Fecha de aceptación: 30 de julio de 2018 
